\title{
Conceptualizing Sensory Emotioncy as a Source of Group Formation
}

\section{Reza Pishghadam}

Professor of Language Education, Professor by Courtesy of Educational Psychology, Ferdowsi University of Mashhad, Iran

\section{Golshan Shakeebaee}

Ph.D. Student in Language Education, Tehran University, Tehran, Iran

Nasim Boustani

Ph.D. Student in Language Education, Ferdowsi University of Mashhad, Iran

\begin{abstract}
An understanding of the qualities that attract people to each other and the tenacious forces that connect them into social units seems to be necessary for the advancement of sound comprehension of interpersonal relationships. Given the fact that the role of senses is accentuated in social relations, the present study intends to benefit from the newly developed concept of sensory emotioncy to predict the perceived similarity. To this end, 24 participants were asked to fill the sensory emotioncy scale. After that, based on the obtained score, they were put into four groups of six, and negotiated about three different topics. The way that participants team up in the groups were tracked, and it was observed that the participants with adjacent sensory emotioncy score tend to team up with each other. In the end, the possible implications of this qualitative study are presented.
\end{abstract}

Keywords: similarity, attraction, emotioncy, involvement, exvolvement 